\title{
Validating innovations to improve recovery after heart surgery
}

\author{
Ali Fatehi Hassanabad, Paul W. M. Fedak \\ Department of Cardiac Science, Section of Cardiac Surgery, Cumming School of Medicine, University of Calgary, Libin Cardiovascular Institute of \\ Alberta, Calgary, Alberta, Canada \\ Correspondence to: Paul W. M. Fedak, MD, PhD. Department of Cardiac Science, Section of Cardiac Surgery, Cumming School of Medicine, \\ University of Calgary, Libin Cardiovascular Institute of Alberta, C880, 1403-29th Street NW, Calgary, Alberta T2N 2T9, Canada. \\ Email: paul.fedak@gmail.com. \\ Comment on: Gulack BC, Kirkwood KA, Shi W, et al. Secondary surgical-site infection after coronary artery bypass grafting: A multi-institutional \\ prospective cohort study. J Thorac Cardiovasc Surg 2018;155:1555-62.e1.
}

Submitted Aug 28, 2018. Accepted for publication Sep 06, 2018.

doi: $10.21037 /$ atm.2018.09.23

View this article at: http://dx.doi.org/10.21037/atm.2018.09.23

Despite advances made in percutaneous procedures for cardiac pathologies, open heart surgery continues to play a major role in the management of a variety of heart diseases. Cardiac surgery has evolved considerably, as it continues to incorporate many advances, including minimally invasive approaches, endoscopic techniques, endovascular modalities, bioengineered materials, and state-of-the art artificial assist devices. Given that cardiac surgery is significantly shaped and driven by the rapid introduction of clinical innovations, it is crucial to routinely assess the impact of new technologies on clinical outcomes $(1,2)$. An astute and evidence-based assessment of the nature and extent of impact, and a critical evaluation of the resulting clinical outcomes will undoubtedly further herald the utility of cutting edge technologies in the optimal surgical treatment of cardiac ailments.

Coronary artery bypass grafting (CABG) is one of the most common operations, with more than 300,000 cases being performed annually in the United States alone (3). Ever since its inception in the 1960s, the operation has undergone a few iterations which, when combined with markedly improved post surgical care, more effective cardiac medications, and an almost flawless cardiopulmonary bypass system, has yielded extraordinary long-term clinical outcomes. In fact, it is one of the best-studied treatment surgeries in medicine, where its performance and efficacy have shone through in a plethora of large randomized clinical trials (4).

For revascularization, the left internal mammary artery remains the primary option for bypassing the left anterior descending coronary artery (5). In selecting a second, third or indeed more bypass grafts, however, the great saphenous vein (GSV) remains the most widely used vessel. This is due to a few favorable factors: relative ease in harvesting the vein, it is not prone to spasms, and its long-term patency has been thoroughly studied $(3,6)$.

The GSV has historically been accessed by making a large incision on the patient's leg, referred to as open vein harvest $(\mathrm{OVH})$. As such, the approach could be associated with undesired sequalae, especially pain and wound complications including infections. These result in delayed ambulation, prolonged length of hospital stay, and potentially increased readmission rates (3). The infection rate associated with OVH ranges from $2 \%$ to $24 \%$ of cases, implying a non-negligible health and economic burden (7). The utility of endoscopic techniques within surgery was introduced in the 1990s. This paved the way for endoscopic vein harvesting $(\mathrm{EVH})$ in cardiac surgery. Over the past three decades EVH has grown in popularity with many centres across the world adopting it as the option of choice. Its use has been supported by studies showing lower postsurgical complications when compared to the traditional OVH approach (7).

In this multi-centre prospective cohort study, Gulack et al. assesses patient risk factors and processes of care associated with secondary surgical-site infection (SSI) after coronary artery bypass surgery. The study considers a few key points pertinent to post operative recovery in patients undergoing a CABG, so the authors should be commended for their initiative. The group has produced a manuscript 
which has a few notable strengths, including: a large sample size; a well-designed methodology; and results which corroborate earlier studies. The authors correctly recognize that the study was not powered to examine the endpoint of secondary SSI, so its predictive power is limited. They also concede the short follow-up duration of 65 days may have not been adequate in fully categorizing patients who had developed an SSI post CABG. Nevertheless, their results showed a $3 \%$ rate for acquiring a secondary SSI, which was associated with an increased body mass index and packed red blood cell transfusion.

Gulack's study attributes their findings to the technique employed in harvesting the SVG. They derive EVH's benefits: fewer complications related to wound infection, such as lower incidence of hematomas, saphenous nerve neuropathy, and neuralgia. Although these advantages have been referenced to in similar studies, EVH has had its fair share of controversy. In particular, some groups have implicated this approach with lower graft patency in intermediate- to long-term follow-up studies. This has been theorized to be secondary to the endothelial damage caused by using a scope (8-11). Other studies have shown the safety of EDV, and refuted higher graft patency failure rates (12-15). In reality, EVH has the potential for improving post-operative recovery, and endothelial damage can be reduced by an experienced user. To fully investigate the clinical outcomes of $\mathrm{EVH}$ versus $\mathrm{OVH}$, more studies are needed $(16,17)$.

To further aid patient recovery post cardiac surgery, our group assessed adhesive-enhanced sternal closure, and demonstrated benefits on functional recovery, respiratory capacity, incisional pain, and analgesic requirements (18). This pilot study underlined the significance of patient recovery post cardiac surgery, and explored methods for improving multiple patient factors, hence paving the way for more research in this area. In another study, we showed the safety and efficacy of using negative pressure wound therapy following $\mathrm{OVH}$, highlighting its benefits in improving postoperative recovery (19).

As we continue to incorporate advancing technologies in cardiac surgery, studies similar to this one should be encouraged as they highlight the importance of objective patient outcomes. Cardiac surgery continues to rapidly evolve in embracing new approaches and methodologies. To ensure these advances have a substantial and lasting imprint on our management of cardiac diseases, a comprehensive and regular analysis is required, and Gulack et al. has provided a step in that direction.

\section{Acknowledgements}

None.

\section{Footnote}

Conflicts of Interest: The authors have no conflicts of interest to declare.

\section{References}

1. Iribarne A, Russo MJ, Moskowitz AJ, et al. Assessing technological change in cardiothoracic surgery. Semin Thorac Cardiovasc Surg 2009;21:28-34.

2. Peterson ED. Innovation and comparativeeffectiveness research in cardiac surgery. $\mathrm{N}$ Engl J Med 2009;361:1897-9.

3. Nezafati P, Kahrom M, Nezafati MH. Endoscopic vein harvesting: the growing role in cardiac surgery. Arch Med Sci Atheroscler Dis 2017;2:e34-6.

4. Sipahi I, Akay MH, Dagdelen S, et al. Coronary artery bypass grafting vs percutaneous coronary intervention and long-term mortality and morbidity in multivessel disease: meta-analysis of randomized clinical trials of the arterial grafting and stenting era. JAMA Intern Med 2014;174:223-30.

5. Likosky DS, Dacey LJ. To use or not to use: a focus on endoscopic vein harvesting. Future Cardiol 2011;7:277-80.

6. Hess CN, Lopes RD, Gibson CM, et al. Saphenous vein graft failure after coronary artery bypass surgery: insights from PREVENT IV. Circulation 2014;130:1445-51.

7. Chernyavskiy A, Volkov A, Lavrenyuk O, et al. Comparative results of endoscopic and open methods of vein harvesting for coronary artery bypass grafting: a prospective randomized parallel-group trial. J Cardiothorac Surg 2015;10:163.

8. Eid RE, Wang L, Kuzman M, et al. Endoscopic versus open saphenous vein graft harvest for lower extremity bypass in critical limb ischemia. J Vasc Surg 2014;59:136-44.

9. Harky A, Balmforth D, Shipolini A, et al. Is endoscopic long saphenous vein harvesting equivalent to open harvesting technique in terms of graft patency? Interact Cardiovasc Thorac Surg 2017;25:323-6.

10. Kopjar T, Dashwood MR. Endoscopic Versus "No-Touch" Saphenous Vein Harvesting for Coronary Artery Bypass Grafting: A Trade-Off Between Wound Healing and Graft Patency. Angiology 2016;67:121-32. 
11. Lopes RD, Hafley GE, Allen KB, et al. Endoscopic versus open vein-graft harvesting in coronary-artery bypass surgery. N Engl J Med 2009;361:235-44.

12. Deppe AC, Liakopoulos OJ, Choi YH, et al. Endoscopic vein harvesting for coronary artery bypass grafting: a systematic review with meta-analysis of 27,789 patients. J Surg Res 2013;180:114-24.

13. Krishnamoorthy B, Critchley WR, Thompson AJ, et al. Study Comparing Vein Integrity and Clinical Outcomes in Open Vein Harvesting and 2 Types of Endoscopic Vein Harvesting for Coronary Artery Bypass Grafting: The VICO Randomized Clinical Trial (Vein Integrity and Clinical Outcomes). Circulation 2017;136:1688-702.

14. Luckraz H, Cartwright C, Nagarajan K, et al. Major adverse cardiac and cerebrovascular event and patients' quality of life after endoscopic vein harvesting as compared with open vein harvest (MAQEH): a pilot study. Open Heart 2018;5:e000694.

15. Nezafati MH, Nezafati P, Amoueian S, et al.

Cite this article as: Fatehi Hassanabad A, Fedak PW. Validating innovations to improve recovery after heart surgery. Ann Transl Med 2018;6(Suppl 1):S13. doi: 10.21037/ atm.2018.09.23
Immunohistochemistry comparing endoscopic vein harvesting vs. open vein harvesting on saphenous vein endothelium. J Cardiothorac Surg 2014;9:101.

16. Grant SW, Grayson AD, Zacharias J, et al. What is the impact of endoscopic vein harvesting on clinical outcomes following coronary artery bypass graft surgery? Heart 2012;98:60-4.

17. Raja SG, Sarang Z. Endoscopic vein harvesting: technique, outcomes, concerns \& controversies. J Thorac Dis 2013;5 Suppl 6:S630-7.

18. Fedak PW, Kieser TM, Maitland AM, et al. Adhesiveenhanced sternal closure to improve postoperative functional recovery: a pilot, randomized controlled trial. Ann Thorac Surg 2011;92:1444-50.

19. Lee AJ, Sheppard CE, Kent WD, et al. Safety and efficacy of prophylactic negative pressure wound therapy following open saphenous vein harvest in cardiac surgery: a feasibility study. Interact Cardiovasc Thorac Surg 2017;24:324-8. 